The chapter dealing with immunization against diphtheria demonstrates, on the other hand, the beneficent effects of the fight against this disease. They are shown by the reduction of notifications of diphtheria and deaths from it to less than one-tenth of those recorded in the years before immunization. Reduction in the fatality-rate of scarlet fever was partly due to penicillin and the sulphonamide drugs and partly to a natural cyclic fall in the virulence of the streptococci which cause this disease. Measles was more prevalent in 1948 than in the previous year; but there were only 327 deaths from it. Trials of a prophylactic serum against measles were in progress. As many parents know, whooping cough was also prevalent in 1948 ; but the fatality-rate $(0.51$ per cent) was lower than in any other year. This disease is, however, still a prominent cause of the deaths of infants. It is especially dangerous during the first year of life and particularly during the first six months. Although special efforts are being made to find a drug to treat it, to improve methods of diag. nosis and to make an effective prophylactic vaccine, the protection of infants from infection remains, at present, the best method of fighting the disease.

The incidence of cerebrospinal fever was low and sporadic ; but notifications of poliomyelitis continued. during the early part of 1948 at a high rate after the epidemic of 1947 and caused much anxiety. The extensive work on typhoid fever, paratyphoid fever, dysentery, enteritis and other diseases of the alimentary canal is described in some detail. That landmark in the battle of man against malaria, namely, the discovery by workers at the London School of Hygiene and Tropical Medicine of the phase of the malarial parasites which lives and multiplies in the human liver before the parasites enter the blood cells, receives the attention it deserves. Some diseases, such as anthrax and leprosy, are rare but demand a great deal of administrative labour and care. The marked fall in the incidence of syphilis recorded in 1947 continued during 1948 , although it has been less marked in the large seaports, and considerable reservoirs of this disease still exist in England and Wales. The incidence of gonorrhœa has also fallen; but it is likely that many women are infected without knowing it.

The number of deaths due to cancer increased, partly because there were more people living at the ages most susceptible to this disease. It increased more in males than in females, and two-thirds of the male increase was due to cancer of the respiratory system. An: interesting section of the report deals with acute rheumatism in children less than sixteen years of age and with chronic rheumatism. Other sections deal with the continuing expansion of the Public Health Laboratory Service, with outbreaks of milk-borne typhoid fever, paratyphoid fever and scarlet fever, with the Hospital Laboratory Service and the National Blood Transfusion Service, and with tuberculosis, mental disease, hospital planning and the dental services.

A survey of nutrition reports little change in the good nutritional state of schcol children and records satisfactory hæmoglobin levels among housewives and expectant mothers. As is well known, the treatment of flour by the 'agene' process has now ceased. The report leaves the reader in no doubt that nutrition, which is so important a means of combating disease of all kinds, is being studied in all its aspects. Not less important is the continued difficulty in providing the nursing and other staff for hospitals, and a chapter is devoted to this acute problem. The report of social survey workers describes some of the methods employed and records no real difference in the amounts of sickness recorded in 1947 and 1948. Another chapter deals with the first World Health Assembly in June 1948 and the international health work arising out of it.

In the second section of the report, the administration of the national health and welfare services are considered, and Part 2 discusses housing, local government, water, river boards and sewerage and its disposal. There are fourteen appendixes which add useful information to the great store of facts recorded in this combined report. It is, as Sir Wilson Jameson says, the work of many hands and is a monument to the effort and care expended upon the many aspects of the national health. 'The nation's gratitude is due to all these men and women who labour continually on its behalf. Whether their jobs are the humbler ones of the nurse or the clerk, or the more responsible ones of the expert, they constitute together a remark. able team. Sir Wilson Jameson, who retired early in $1950^{1}$, has played a great part in building up and eo-ordinating their efforts and can look back on a fine record during his term of office. He pays a fine tribute to Sir George Newman, who died in $1948^{2}$ and who, as a predecessor in office to Sir Wilson, had guided public health activities for a quarter of a century.

G. LAPAGE

Nature, 165, 753 (1950).

${ }^{2}$ Nature, 161, 1001 (1948).

\section{RESEARCH AND DEVELOPMENT AT BAKELITE, LTD.}

$\mathrm{O}^{\mathrm{N}}$ June 21, Bakelite, Ltd., opened their new research and development laboratories at Birmingham to a representative gathering of those interested in both the scientific and industrial progress of high-polymer science and technology. Although only part of the manufacturing site of this concern is located at Tyseley in Birmingham, the research and development activities of the firm are mainly centred there. The visit presented a unique opportunity for seeing how one of the old-established branches of the industry has developed on the industrial side, and how, with the advance of knowledge in the science of high polymers, that science has been integrated with technology-a first pre-requisite of a healthy and forward-looking industry.

One of the major activities concerns the thermosetting resins derived from phenols and formaldehyde and from urea and formaldehyde. In spite of the extensive use of such resins in a host of applications such as laminated materials for electrical purposes, cements and adhesives, moulding powders and oil. soluble resins for paints, the chemical process involved in the manufacture of the resin as such is to a very large extent built on empirical knowledge. That does not mean that precise methods of the control of processes and the checking of the quality of the product are not used at every stage. In fact, the visit demonstrated clearly just how much can be contributed by instrumentation to the reproducibility and efficiency of the manufacturing processes $\mathrm{em}$ ployed. 'The older autoclaves or 'stills', as they are called, were devoid of control devices, and the whole success of synthesis depended to a large extent on the skill of the operators. In the most up-to-date 
stills much of the human factor has been replaced by devices to ensure that the cycle of events in such a batchwise process is accurately reproduced time and again, so that the structure and molecular size of the resin may be kept within defined limits. There could be no better demonstration for advocates of the more extensive use and also development of instruments for application in industrial chemical processes.

The reason for the empirical development of the method of synthesis of such polymers was simply due to the fact that, forty or fifty years ago, academic interest in these matters was negligible. Indeed, it is true to say that empiricism was the only method of approach, but it has carried the industry a long way. With the considerable growth of purely scientific interest in high polymers, it was evident that the time had come for a closer integration of science and technology in the hope that science will help the technologist to achieve even greater development and exploitation of plastic materials. This is primarily the reason for the building and equipping by Bakelite, Ltd., of the first stage of research and development laboratories, to carry the above-mentioned ideas as rapidly as possible into practice.

The new building is a steel-framed construction with cavity-brick walls of a pleasing shade. Inside, the walls are plastered and furnished with cream paint. Heating is by a hot-water system supplied from an automatically controlled oil-fired boiler. The services are carried along the corridors in ducts with easy access. In the laboratories, ducts in the floors at suitable intervals provide for flexibility in the partitioning of benches and in the erection of special apparatus. Exhaustion of fume cupboards is by individual fans. Many of the furnishings-doors, library shelving, etc.-utilize resin-bonded laminated wood veneers to good effect. Laboratory benches, cupboards and wood-block flooring are constructed by the less-expensive conventional methods in hard wood. The laboratories have high ceilings, and the fixed benches are well spaced so that large-scale laboratory apparatus may be easily erected. Windows are of large area and the sills are high, so that benches with shelves can easily be fitted below the sills. Fluorescent lighting of high intensity is fixed to the ceiling, which is covered with asbestos sound-insulating material. Non-structural partitions and also metalglass partitions make for the maximum internal flexibility of laboratory arrangement.

On the research side, a considerable volume of work is being carried out on the mechanism of the phenol-formaldehyde condensation process itself, in order to give a complete picture of the mechanism of the reaction and of the precise structure of the intermediates as well as the final products of synthesis. There was exhibited a whole range of intermediate products synthesized by rational organic methods. Similarly, methods of molecular distillation have enabled some of these intermediates to be isolated from reaction mixtures similar to those used on the large scale. Since the number of isomers present can be very large, owing to the existence of three reactive positions in the phenol molecule, infra-red and ultraviolet and spectroscopic methods are being used for structure determination. Careful studies are also being made of the kinetics of the reaction, often with the above-mentioned specially synthesized intermediates, so that the complexities of the process may be sorted out stage by stage and a closer insight gained into the various stages of this very com. plicated polycondensation process.
Closely associated with the fundamental research is the development side, which is fully equipped with small-scale apparatus to explore the ever-widening application of existing materials in all directions and in investigating eventually the potentialities of new materials. The facilities for evaluating the mechanical and electrical behaviour of all materials are available to the research and development departments.

There is thus added another unit to industrial research in Great Britain which will ensure that science is applied to the maximum profitable extent to an industry which might well have become traditional and wholly empirical in character, had those in charge not realized the vital necessity of bringing in the fundamental scientific approach at all stages.

\section{SOUTH WESTERN NATURALISTS' UNION} ANNUAL CONFERENCE

7 HE South Western Naturalists' Union held its twenty-third annual conference at Marlborough, Wiltshire, during May 26-29, by invitation of the Marlborough College Natural History Society. Members attending the conference (about seventy) were received by the Master of Marlborough College, Mr. F. M. Heywood, in the Science Building, Marlborough College, on the evening of May 26, after which Mr. W. E. V. Young lectured on "Avebury Stone Circle". This lecture, which is to be known as the Pedler Lecture, had been financed by the British Association for the Advancement of Science from the Pedler Fund.

On the morning of May 27 a number of short talks were given by Mr. L. G. Pierson, Mr. C. R. M. Prentice, Mr. F. H. P. Barber and Mr. H. J. Killick on the birds, Lepidoptera, geology and botany of the region. On the evening of May 28, in the Memorial Hall, Marlborough College, Mr. Peter Scott, president of the Union, gave his presidential address, his subject being "Nature Reserves and their Functions, with Special Reference to the Severn Wild Fowl Trust". The address was illustrated by coloured films.

The general meeting of the Union took place on May 29, at which Mr. A. O. Rowden put forward the following resolution: "This Annual General Meeting of the South Western Naturalists' Union embracing eighteen societies domiciled in the South West of England in conference at Marlborough, this 29 th day of May, 1950, views with apprehension and alarm the increasing tendency of various interests to act detrimentally to the natural and archæological amenities of Dartmoor and urges that it be designated a national park with the least possible delay". This resolution was carried, and the secretary was instructed to send copies to the Minister of Town and Country Planning, the chairman of the National Parks Committee and the clerk to the Devon County Council.

In a closing address, Sir Lowis Fermor, vicepresident of the Union, stressed the thanks of the conference to the members of Marlborough College for the excellent way in which they had organised the general arrangements. At the conclusion of this highly successful conference Mr. Peter Scott was re-elected president for 1951 . 